\title{
Synthesis of Novel Peptide Inhibitors of Thrombin-induced Platelet Activation
}

\author{
Fernanda M. Burke ${ }^{1}$, Mark Warnock ${ }^{2}$, Alvin \\ H. Schmaier ${ }^{3}$ and Henry I. Mosberg ${ }^{1, *}$ \\ ${ }^{1}$ Department of Medicinal Chemistry, College of Pharmacy, \\ University of Michigan, 428 Church Street, Ann Arbor, MI 48109- \\ 1065, USA \\ ${ }^{2}$ Department of Internal Medicine, University of Michigan, Ann \\ Arbor, MI 48109-0368, USA \\ ${ }^{3}$ Division of Hematology/Oncology, Department of Medicine, Case \\ Western Reserve University, Cleveland, OH, 44106, USA \\ *Corresponding author: Henry I. Mosberg, him@umich.edu
}

Inhibitors of the activation of platelet aggregation have promise as important therapeutic agents for the management of acute coronary syndrome (ACS). Platelet activation by thrombin, a serine protease, occurs by binding to and cleavage of the extracellular $\mathbf{N}$-terminal domains of protease-activated receptors 1 and 4 (PAR1 and PAR4). The proteolysis of the PARs exposes new tethered ligands that then signal through transmembrane domains to initiate platelet activation as a downstream effect. A pentapeptide cleavage product of bradykinin with the sequence ArgPro-Pro-Gly-Phe serves as a thrombin inhibitor by blocking $\alpha$ - and $\gamma$-thrombin-induced platelet aggregation. Analogs of RPPGF have been prepared that result in improved inhibition of thrombin activation of platelets. Specific amino acid residues required for activity against platelet aggregation have been identified, and a lead compound, rOicPaPhe(p-Me)-NH $\mathrm{NH}_{2}$ (FM19), has been developed. FM19, which completely inhibits threshold $\gamma$-thrombin-induced platelet aggregation at a concentration of $16 \pm 4 \mu \mathrm{M}$, represents an important lead compound in the development of inhibitors of thrombin-mediated platelet aggregation for treatment of ACS.

Key words: bradykinin, protease-activated receptor, platelet aggregation, thrombin, thrombin receptor

Received 14 September 2006, revised 11 October 2006, accepted for publication 13 October 2006

Acute coronary syndrome (ACS) refers to a number of conditions, from unstable angina to myocardial infarction (MI), which most often develop as a result of reduced coronary artery blood supply because of ruptured atherosclerotic plaque (1). Approximately $90 \%$ of Mls result from an acute thrombus that obstructs an atherosclerotic coronary artery (1). Therefore, modulating the activity of the hemostatic system is both treatment and prevention of these serious and too often fatal medical conditions.

Thrombin has an important role in hemostasis and thrombosis by being the main clotting enzyme as well as a potent platelet activator (2). Thrombin has two substrates on platelets, protease-activated receptors 1 and 4 (PAR1 and PAR4), that when stimulated lead to platelet activation. The PARs are G-protein-coupled receptors that have a novel mechanism in which an extracellular proteolytic cleavage event is translated into a transmembrane signal. These receptors carry their own ligand, which remains cryptic until an $\mathrm{N}$-terminal fragment of the receptor is cleaved by thrombin (3). Once activated by thrombin-mediated proteolysis, these G-proteincoupled receptors' tethered ligands bind intramolecularly to induce signaling to activate platelets (4). To date, only inhibitors to arachidonic acid- or ADP-induced platelet aggregation have been developed for clinical use. Development of inhibitors to thrombininduced platelet activation would advance the field.

Bradykinin, a nonapeptide, is released from the plasma proteins, high- and low-molecular weight kininogen through the action of plasma kallikrein (5). Bradykinin increases vascular permeability, dilates blood vessels, contracts non-vascular smooth muscle, and causes pain. This short-lived vasodilator is degraded by angiotensin-converting enzyme to produce a pentapeptide with sequence Arg-Pro-Pro-Gly-Phe (RPPGF) (6). This pentapeptide, along with kininogen and bradykinin, inhibits thrombin-induced platelet activation and aggregation by interacting with the active site of thrombin and with the thrombin cleavage sites of PAR1 and PAR4 receptors $(7,8)$. Therefore, RPPGF and its analog rOicPGF- $\mathrm{NH}_{2}$ are leads for the development of a selective and potent inhibitor of thrombin-induced platelet activation $(9,10)$. This study reports substitutions made to the rOicPGF-NH $\mathrm{N}_{2}$ sequence designed to produce a more potent thrombin receptor activation inhibitor for the management of ACS, and describes the discovery of a novel lead compound.

\section{Materials and Methods}

\section{Peptides and reagents}

Standard single-letter abbreviations are used to describe L-amino acids and lowercase letters are used to represent D-amino acids. RPPGF and rOicPGF were synthesized by Multiple Peptides Systems, Inc. (San Diego, CA, USA). The remaining peptides were prepared by standard solid-phase peptide synthesis methods on a Applied Biosystems, Inc. (Foster City, CA, USA) Model 431A peptide synthesizer $(11,12)$. The peptides were assembled on peptide amide linker polyethylene glycol polystyrene (PAL-PEG-PS) resin (Applied Biosystems, Warrington, UK) using standard Fmoc-based chemistry (13). 


\section{Burke et al.}

The protected amino acids Fmoc-D-Arg (Pbf), Fmoc-Phe( $p$-Me), Fmoc$\operatorname{Phe}(p-\mathrm{Br})$, Fmoc-Phe $(p-I)$, Fmoc-Phe $\left(p-\mathrm{NO}_{2}\right)$, Fmoc-Pro, Fmoc-Oic, Fmoc-D-Ser(t-Bu), Fmoc-Lys(biotin), and Fmoc-D-Ala were obtained from Advanced ChemTech (Louisville, KY, USA). Unless otherwise stated, all reagents were HPLC grade and purchased from Fisher Scientific (Fair Lawn, NJ, USA).

The synthesis occurred in a cycle that was initiated by the swelling of the resin $(0.25 \mathrm{mmol})$ in dichloromethane (DCM) followed by deprotection or removal of the Fmoc group from the resin with piperidine (Aldrich, Milwaukee, WI, USA), followed by extensive solvent wash and, subsequently, by coupling of Fmoc-protected amino acid (1 mmol). Coupling was facilitated by o-benzotriazol-1-yl- $N, N, N^{\prime}, N^{\prime}$ tetramethyl uronium hexafluorophosphate (HBTU; Applied Biosystems), which was dissolved in a solution of 1-hydroxybenzotriazole (HOBt; Applied Biosystems) and N,N-dimethylformamide (DMF). The protected amino acid was dissolved in the HBTU/HOBt solution along with additional $\mathrm{N}$-methylpyrrolidone (NMP). The reaction was carried out in the presence of $2.0 \mathrm{M} \mathrm{N}, \mathrm{N}$-diisopropylethylamine (DIEA; Applied Biosystems), which created the basic environment necessary for the activation of the amino acid residue (14). The activated amino acid reacted with the deprotected amino-terminal of the growing peptide chain. The final step in each coupling cycle involved acetylation of unreacted amino groups by addition of 10 fold excess of $0.5 \mathrm{M}$ acetic anhydride, $0.125 \mathrm{M}$ DIEA, and $0.015 \mathrm{M}$ $\mathrm{HOBt}$ in NMP. This sequence of steps was repeated until the fulllength, resin-bound peptide was completed. The resin was filtered and washed with DCM and ethyl alcohol (EtOH) to complete the solid-phase synthesis.

Trifluoroacetic acid/ $\mathrm{H}_{2} \mathrm{O} /$ thioanisole/ethylenedithiol solution (9:0.5: 0.25:0.25, v/v/v/v; Pierce, Rockford, IL, USA)/(Applied Biosystems) was used to cleave the peptide from the resin and simultaneously remove the side chain-protecting groups. The peptide solution was filtered from the resin and then subjected to preparative reversephase high-performance liquid chromatography (RP-HPLC) to afford the target peptide. The HPLC conditions were: column, Vydac C18, $2.5 \times 22 \mathrm{~cm}$; mobile phase, (A) water with $0.1 \%$ TFA, (B) acetonitrile with $0.1 \%$ TFA; gradient, (A/B) from $100 / 0$ to $60 / 40$ over $80 \mathrm{~min}$; flow rate, $10 \mathrm{~mL} / \mathrm{min}$; detection, UV at $230 \mathrm{~nm}$. The purity of all peptides was $\geq 99 \%$ as analyzed by HPLC. Final product molecular weight was confirmed by electrospray mass spectrometry (ThermoFinnigan, San Jose, CA, USA).

\section{Platelet aggregation}

Each peptide was examined for its ability to inhibit $\gamma$-thrombininduced platelet aggregation of human platelet-rich plasma (PRP) as described by Hasan et al. $(8,10)$. Fresh whole blood from normal human donors was collected into a syringe containing $3.8 \%$ sodium citrate, to a final concentration of $0.38 \%$ sodium citrate $11: 9$ citrate/blood). Whole blood was centrifuged at $180 \times g$ (Beckman GRP Centrifuge, Schaumburg, IL, USA) for 10 min at room temperature to prepare PRP. Platelet-poor plasma (PPP) was prepared by centrifugation of PRP at $1000 \times g$ for $20 \mathrm{~min}$ at room temperature or by centrifugation at $10000 \times g$ for 2 min (Microcentrifuge $E$, Beckman Instruments, Palo Alto, CA, USA). The platelets were counted on a Coulter counter (Model Z, Coulter Electronics, Hialeah, FL,
USA), and PRP was adjusted to a platelet count of $2.5 \times 10^{8}$ platelets $/ \mathrm{mL}$, using PPP prior to all platelet aggregation studies. A Chronolog dual-channel aggregometer (Havertown, PA, USA) was used to assess platelet aggregation by recording the increase in light transmittance through a stirred suspension of PRP maintained at $37^{\circ} \mathrm{C}$ in the cuvette. Variable concentrations of $\gamma$-thrombin (Haematologic Technologies, Essex Junction, VT, USA) were added to the PRP to determine the threshold concentration for maximal percentage aggregation, i.e. the minimal concentration of the agonist to induce full aggregation and secretion. $\gamma$-Thrombin (Haematologic Technologies; approximately $3000 \mathrm{U} / \mathrm{mg}$ specific activity) was used for these studies because this form of the enzyme is unable to bind and proteolyze plasma fibrinogen in plasma to produce a clot. Peptides were dissolved in fresh HEPES-Tyrodes buffer $(\mathrm{pH}=7.40)$ and added at concentrations ranging from $5 \mu \mathrm{M}$ to $1 \mathrm{~mm}$ to the PRP in the cuvette, allowing the baseline to stabilize. Platelet aggregation was initiated by the addition of threshold amounts of $\gamma$-thrombin (usually 30-70 nм for human platelets) determined for that donor on the day of examination. The aggregation was allowed to proceed for $5 \mathrm{~min}$ and the minimal concentration of each peptide to achieve $100 \%$ inhibition of platelet aggregation $\left(\mathrm{IC}_{100}\right)$ was determined.

\section{Results and Discussion}

To develop analogs related to RPPGF with increased potency for inhibition of thrombin-induced platelet aggregation, we focused our initial efforts on substituting residues at positions 4 and 5 . Previous work employing both combinatorial methods and rational drug design indicated that the substitution of the first residue with D-Arg and replacement of $\mathrm{Pro}^{2}$ by Oic, known to improve potency of bradykinin antagonists; while maintaining proline in the third position of the sequence, led to pronounced improvements in potency, and resulted in the lead compound, rOicPGF-NH 2 (TH146) $(10,15,16)$. The goal of the current efforts was to optimize the remaining positions by preparing analogs with substitutions at $X x x^{4}$ and $X x x^{5}$. The results of these substitutions are summarized in Tables 1 and 2 , where data are reported as the minimal concentration of the inhibitor to completely block threshold $\gamma$-thrombin-induced platelet aggregation $(7,8,10)$. Several previously synthesized and reported compounds are also included for comparison.

Table 1 presents compounds with replacements for Gly at position 4 of rOicPGF-NH $\mathrm{NH}_{2}$ (TH146). As glycine has no side chain and can assume conformations allowed for both L- and D-amino acids, alanine, the most conservative substitution for glycine, was examined in both L- and D-configurations (compounds $\mathbf{1}$ and $\mathbf{2}$, respectively). As seen in Table 1, compound 2, which showed 100\% inhibition of platelet aggregation at $56 \mu \mathrm{M}$, is 10 -fold more potent than compound $\mathbf{1}$ and 2.5-fold more potent then TH146 in $\gamma$-thrombininduced platelet aggregation.

The successful results observed during the testing of $\mathbf{2}$, encouraged us to explore further D-amino acid substitutions in position 4. Among the remaining D-amino acid-substituted analogs, compound 3, rOic$\mathrm{PnF}_{-} \mathrm{NH}_{2}$ showed a modest improvement over TH146 with 100\% inhibition of platelet aggregation at $83 \mu \mathrm{M}$, slightly less potent than $\mathbf{2}$. The remaining analogs in this series had similar activity independent 
Table 1: Modifications at position 4 with phe at position 5

\begin{tabular}{lll}
\hline Compounds & Sequence & $\begin{array}{l}\text { Inhibition of threshold } \\
\text { platelet aggregation }\left(\mu \mathrm{M} \pm \mathrm{SEM}^{\mathrm{a}}\right)\end{array}$ \\
\hline RPPGF $^{\mathrm{b}}$ & RPPGF & $680 \pm 280$ \\
TH146 & rOicPGF-NH & $140 \pm 20$ \\
$\mathbf{1}$ & rOicPAF-NH & $550 \pm 166$ \\
$\mathbf{2}$ & rOicPaF-NH & $56 \pm 16$ \\
$\mathbf{3}$ & rOicPnF-NH & $83 \pm 17$ \\
$\mathbf{4}$ & rOicPkF- $\mathrm{NH}_{2}$ & $133 \pm 33$ \\
$\mathbf{5}$ & rOicPfF-NH & $133 \pm 33$ \\
$\mathbf{6}$ & rOicPpF-NH & $167 \pm 33$ \\
$\mathbf{7}$ & rOicPIF-NH & $300 \pm 100$ \\
$\mathbf{9}$ & rOicPdF-NH & $567 \pm 233$ \\
$\mathbf{1 0}$ & rOicPqF-NH & $400 \pm 100$ \\
$\mathbf{1 1}$ & rOicP-(D-Abu)-F- $\mathrm{NH}_{2}$ & $275 \pm 75$ \\
$\mathbf{1 2}$ & rOicP-(D-Orn)-F-NH & $250 \pm 87$ \\
$\mathbf{1 3}$ & rOicP-(D-Nle)-F- $-\mathrm{NH}_{2}$ & $275 \pm 75$ \\
\hline
\end{tabular}

a Data presented are the mean \pm SEM of $n>3$ independent experiments The values given represent the minimal concentration of peptide necessary to inhibit $100 \%$ of threshold $\gamma$-thrombin-induced platelet aggregation $\left(\mathrm{IC}_{100}\right)$. ${ }^{\mathrm{b}}$ From Hasan et al. (7).

Table 2: Modifications at position 5 with gly at position 4

\begin{tabular}{lll}
\hline Compounds & Sequence & $\begin{array}{l}\text { Inhibition of threshold } \\
\text { platelet aggregation }\left(\mu \mathrm{M} \pm \mathrm{SEM}^{\mathrm{a}}\right)\end{array}$ \\
\hline RPPGF $^{\text {b }}$ & RPPGF & $680 \pm 280$ \\
TH146 & rOicPGF-NH & $140 \pm 20$ \\
$\mathbf{1 4}$ & rOicPG-2-Nal-NH & $50 \pm 0$ \\
$\mathbf{1 5}$ & rOicPGE-NH & $\mathrm{NE}$ \\
$\mathbf{1 6}$ & rOicPG-Nle-NH & $\mathrm{NE}$ \\
$\mathbf{1 7}$ & rOicPGF( $p$-F)- $\mathrm{NH}_{2}$ & $200 \pm 0$ \\
$\mathbf{1 8}$ & rOicPGf-NH & $833 \pm 144$ \\
$\mathbf{1 9}$ & rOicPGW-NH & $350 \pm 87$ \\
$\mathbf{2 0}$ & rOicPGH-NH & $\mathrm{NE}$ \\
$\mathbf{2 1}$ & rOicPG-1-Nal- $\mathrm{NH}_{2}$ & 200 \\
$\mathbf{2 2}$ & rOicPGR-NH & $\mathrm{NE}$ \\
$\mathbf{2 3}$ & rOicPGY-NH & $300 \pm 100$ \\
\hline
\end{tabular}

a Data presented are the mean \pm SEM of $n>3$ independent experiments. The values given represent the minimal concentration of peptide necessary to inhibit $100 \%$ of threshold $\gamma$-thrombin-induced platelet aggregation $\left(I_{100}\right)$. NE represents no effect or $\geq 1000 \mu \mathrm{M}$ activity.

${ }^{\mathrm{b}}$ From Hasan et al. (7).

of the chemical nature of the residue side chain. Consequently, the trend observed in these peptides was that the requirement for residue 4 seemed to be primarily related to the configuration of the amino acid residue, with the actual side chain having a relatively modest effect. A possible explanation is that the D-stereochemistry moves the side chain 'out of the way' while helping to orient the rest of the molecule. This assumption would be consistent with the optimal activity displayed by $\mathbf{2}$, with the small alanine side chain.

In parallel with the examination of varying $X x x^{4}$, we also varied $X x x^{5}$ of the lead compound TH146. The data for the rOicPG-Xxx ${ }^{5}$ $\mathrm{NH}_{2}$ series are presented in Table 2, in which it is clearly observed that L-amino acids are preferred over D-amino acids. This trend is exemplified in the sharp decrease in activity in compound $\mathbf{1 8}$, with
D-phenylalanine at position $5\left(\mathrm{IC}_{100}=833 \mu \mathrm{M}\right)$, in comparison with TH146 $\left(\mathrm{IC}_{100}=140 \mu \mathrm{M}\right)$. In addition, it appears that larger aromatic groups are preferred while aliphatic and polar groups are not well tolerated. The most potent compound in this series, compound $\mathbf{1 4}$,

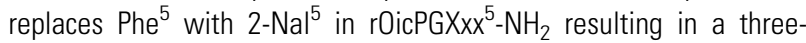
fold improvement over $\mathrm{TH} 146\left(\mathrm{IC}_{100}=50 \mu \mathrm{M}\right)$.

Following the results from our two initial series, we attempted to combine the best substitutions observed in the singly modified $X x x^{4}$ and $X x x^{5}$ series, but unfortunately the results do not appear to be additive. On the contrary, as shown in Table 3, the projected best analog, compound $\mathbf{2 5}$ is only slightly more potent than TH146 $\left(I C_{100}=100 \mu \mathrm{M}\right)$. The explanation for the observed result may be related to steric and conformational restrictions imposed on the doubly substituted peptide, with a less flexible backbone (due to D-alanine at position 4) and the bulky side chain of 2-Nal. Thus, we chose to examine other possible aromatic replacements for 2-Nal at position 5 .

Consequently, as shown in Table 3, we introduced several variations of Phe that, like the successful 2-Nal ${ }^{5}$ substitution, were larger, aromatic, and lipophilic. In the initial analogs of the rOicPG- $X x x^{5}-\mathrm{NH}_{2}$ series, we chose to use Phe derivatives as a means of probing the requirements for interaction with the target receptor. Phe is present in the original lead, RPPGF, and, as seen in Table 2, the aromatic nature of $\mathrm{Phe}^{5}$, appears to be essential for inhibition of platelet activation. As a first group, we chose to use small (methyl), intermediate (chloro), and large (biphenyl) lipophilic substituents at the para-position of the phenyl ring of phenylalanine. In this initial small sample of synthesized analogs, there was a clear preference for the smallest substituent at the para-position of Phe. The p-methylphenylalanine containing compound $\mathbf{2 7}$ was 3.5 -fold more potent than compound 2, 42.5-fold more potent than RPPGF, and had a ninefold increase in potency relative to TH146 in $\gamma$-thrombininduced platelet aggregation.

Table 4 presents the results from our attempts to examine the key features of $\mathbf{2 7}$ that are required for its anticoagulant activity. In this series, we selected a variety of Phe derivatives with a wide range of substituents. We also examined several analogs that retained the $p$-methylphenylalanine at the fifth position, but included modifications at the fourth position that had shown activity in the $\mathrm{rOicP}-\mathrm{Xxx}{ }^{4}-\mathrm{Phe}(p-\mathrm{Me})-\mathrm{NH}_{2}$ series. As seen in Table 4, several

Table 3: Modifications at position 5 with D-ala in position 4

\begin{tabular}{lll}
\hline Compounds & Sequence & $\begin{array}{l}\text { Inhibition of threshold } \\
\text { platelet aggregation }\left(\mu \mathrm{M} \pm \mathrm{SEM}^{\mathrm{a}}\right)\end{array}$ \\
\hline RPPGF $^{\text {b }}$ & RPPGF-NH & $680 \pm 280$ \\
TH146 & rOicPGF-NH & $140 \pm 20$ \\
$\mathbf{2 4}$ & rOicPaF-NH & $56 \pm 16$ \\
$\mathbf{2 5}$ & rOicPa-2-Nal-NH & $100 \pm 35$ \\
$\mathbf{2 6}$ & rOica-Bip-NH & $200 \pm 100$ \\
$\mathbf{2 7}$ (FM19) & rOicPaF(p-Me)-NH & $16 \pm 4$ \\
\hline
\end{tabular}

${ }^{a}$ Data presented are the mean \pm SEM of $n>3$ independent experiments. The values given represent the minimal concentration of peptide necessary to inhibit $100 \%$ of threshold $\gamma$-thrombin-induced platelet aggregation $\left(I C_{100}\right)$. ${ }^{b}$ From Hasan et al. (7). 
Table 4: Modifications to positions 4 and 5 compared with 27

\begin{tabular}{|c|c|c|}
\hline Compounds & Sequence & $\begin{array}{l}\text { Fold decrease in the inhibition } \\
\text { of platelet aggregation } \\
\text { potency versus FM19 }\end{array}$ \\
\hline 27 (FM19) & rOicPaF(p-Me)-NH ${ }_{2}$ & $1^{\mathrm{a}}$ \\
\hline 28 & rOicPaF(p-CI)-NH & 2.75 \\
\hline 29 & rOicPsF(p-Me)-NH & 0.81 \\
\hline 30 & rOicPnF( $p-\mathrm{Me})-\mathrm{NH}_{2}$ & 4 \\
\hline 31 & rOicPa-Hfe-NH ${ }_{2}$ & 8 \\
\hline 32 & rOicPaF $\left(p-\mathrm{NH}_{2}\right)-\mathrm{NH}_{2}$ & 8 \\
\hline 33 & rOicPaF $(p-\mathrm{Br})-\mathrm{NH}_{2}$ & 1.1 \\
\hline 34 & rOicPa(p-But)--NH ${ }_{2}$ & 2 \\
\hline 35 & rOicPaF(p-CN)-NH & 2 \\
\hline 36 & $\mathrm{rOicPaF}(p-I)-\mathrm{NH}_{2}$ & 1 \\
\hline 37 & rOicPaF(2-Me)-NH & 2 \\
\hline 38 & rOicPaF(3-Me)--NH & 4 \\
\hline 39 & rOicPaF $\left(p-\mathrm{NO}_{2}\right)-\mathrm{NH}_{2}$ & 3 \\
\hline 40 & rOicPa-Phg-NH ${ }_{2}$ & 2 \\
\hline
\end{tabular}

aThe data represent the fold increase in concentration of the peptide necessary to inhibit threshold $\gamma$-thrombin-induced platelet aggregation when compared with compound $\mathbf{2 7}$ (FM19) $\left(\mathrm{IC}_{100}=16 \pm 4 \mu \mathrm{M}\right)$.

analogs display potency comparable with that of $\mathbf{2 7}$. In particular 29, 33, and $\mathbf{3 6}$ are essentially equipotent with 27. Although incomplete, these initial structure-activity relationship (SAR) data suggest that lipophilic para-substituents on $\mathrm{Phe}^{5}$ lead to favorable results and that, as observed in Table 1, small D-amino acids are preferred in position 4 of the peptide. Further SAR studies are in progress.

\section{Conclusions}

Several trends were observed in this series of peptides synthesized with the aim of inhibiting thrombin-mediated platelet aggregation. The fourth position of the peptide rOicPGF-NH $\mathrm{NH}_{2}$ has a preference for D-amino acids, but is relatively indiscriminant with regard to the actual amino acid residue and its side chain properties. The presence of an aromatic ring on the side chain of the amino acid in position 5 is preferred over all other amino acid side chains, with Phe( $p$-Me) displaying the best activity thus far. In compound 27, [rOicPaPhe $(p-\mathrm{Me})-\mathrm{NH}_{2}$ ], known as FM19, we have developed a more potent inhibitor $\left(\mathrm{IC}_{100}=16 \mu \mathrm{M}\right)$ of $\gamma$-thrombin-induced platelet aggregation, which represents an order of magnitude improvement over previous RPPGF-related inhibitors. Further studies are underway to extend the SARs of FM19-related analogs and elucidating its mechanism of action.

\section{Acknowledgments}

This work was supported by the University of Michigan Pharmacological Sciences Training Program (GM07767 NIGMS; FMB), the University of Michigan College of Pharmacy Cresswell and Blake Fellowships (FMB), Grant No. 1607 from the Michigan Economic
Development Corporation (HIM, AHS), and NIH grants HL52779, HL61081, and HL61981 (AHS).

\section{References}

1. Paoli G., Merlini P.A., Ardissino D. (2005) Direct thrombin inhibitors for the treatment of acute coronary syndromes and during percutaneous coronary interventions. Curr Pharm Des;11:39193929.

2. Chung A.W., Jurasz P., Hollenberg M.D., Radomski M.W. (2002) Mechanisms of action of proteinase-activated receptor agonists on human platelets. Br J Pharmacol;135:1123-1132.

3. Coughlin S.R. (2000) Thrombin signalling and protease-activated receptors. Nature;407:258-264.

4. Callahan K.P., Malinin A.I., Gurbel P.A., Alexander J.H., Granger C.B., Serebruany V.L. (2001) Platelet function and fibrinolytic agents: two sides of a coin? Cardiology;95:55-60.

5. Colman R.W., White J.V., Scovell S., Stadnicki A., Sartor R.B. (1999) Kininogens are antithrombotic proteins in vivo. Arterioscler Thromb Vasc Biol;19:2245-2250.

6. Murphey L.J., Hachey D.L., Oates J.A., Morrow J.D., Brown N.J. (2000) Metabolism of bradykinin in vivo in humans: identification of BK1-5 as a stable plasma peptide metabolite. J Pharmacol Exp Ther;294:263-269.

7. Hasan A.A., Warnock M., Srikanth S., Schmaier A.H. (2001) Developing peptide inhibitors to thrombin activation of platelets from bradykinin analogs. Thromb Res;104:451-465.

8. Hasan A.A., Warnock M., Nieman M., Srikanth S., Mahdi F., Krishnan R. et al. (2003) Mechanisms of Arg-Pro-Pro-Gly-Phe inhibition of thrombin. Am J Physiol Heart Circ Physiol;285: H183-193.

9. Hasan A.A., Amenta S., Schmaier A.H. (1996) Bradykinin and its metabolite, Arg-Pro-Pro-Gly-Phe, are selective inhibitors of alphathrombin-induced platelet activation. Circulation;94:517-528.

10. Nieman M.T., Warnock M., Hasan A.A., Mahdi F., Lucchesi B.R., Brown N.J. et al. (2004) The preparation and characterization of novel peptide antagonists to thrombin and factor VIla and activation of protease-activated receptor 1. J Pharmacol Exp Ther;311: 492-501.

11. Barany G., Merrifield R.B. (1980) The Peptides. Analysis, Synthesis, Biology. New York: Academic Press.

12. Stewart J.M., Young J.D. (1984) Solid-Phase Peptide Synthesis, 2nd edn. Rockford, Illinois: Pierce Chemical Company.

13. Fields G.B., Noble R.L. (1990) Solid phase peptide synthesis utilizing 9-fluorenylmethoxycarbonyl amino acids. Int J Pept Protein Res;35:161-214.

14. Fields C.G., Lloyd D.H., Macdonald R.L., Otteson K.M., Noble R.L. (1991) HBTU activation for automated Fmoc solid-phase peptide synthesis. Pept Res:4:95-101.

15. Lembeck F., Griesbacher T., Eckhardt M., Henke S., Breipohl G., Knolle J. (1991) New, long-acting, potent bradykinin antagonists. Br J Pharmacol;102:297-304.

16. Stewart J.M. (2004) Bradykinin antagonists: discovery and development. Peptides;25:527-532. 